\title{
Effects of Nitroglycerin on Regional Myocardial Blood Flow in Coronary Artery Disease
}

\author{
Lawrence D. Horwitz, Richard Gorlin, Warren J. Taylor, and \\ HARVEY G. KeMP \\ From the Cardiovascular Division, Department of Medicine and the Division \\ of Thoracic and Cardiac Surgery, Department of Surgery, Peter Bent Brigham \\ Hospital and Harvard Medical School, Boston, Massachusetts 02115
}

\begin{abstract}
A в S T R A C T Regional myocardial blood flow before and after sublingual nitroglycerin was measured in 10 patients with coronary artery disease. During thoracotomy, ${ }^{133} \mathrm{Xe}$ was injected directly into the subepicardium in diseased regions of the anterior left ventricular wall, and washout rates were recorded with a scintillation counter. All disappearance curves were closely approximated by two exponential decays analyzed as two parallel flow systems by the compartmental method. The appearance of a double exponential decay pattern in diseased regions suggests that the slow phase was associated with collateral blood flow, although nonhomogeneous myocardium-to-blood partition coefficients for xenon cannot be excluded. Nitroglycerin increased the rapid phase flow in 9 of 10 patients and the slow flow in 7 of 10 patients. Average flow increased in 9 of the 10 patients $(P<0.01)$. Mean rapid phase flow in the control state was $110 \mathrm{ml} / 100 \mathrm{~g}$ per min and after nitroglycerin increased to $132 \mathrm{ml} / 100 \mathrm{~g}$ per $\min (P<0.01)$; slow phase flow increased from $12 \mathrm{ml} / 100 \mathrm{~g}$ per min to $15 \mathrm{ml} / 100 \mathrm{~g}$ per min $(P<0.05)$. It is concluded that, under these conditions, nitroglycerin improves perfusion in regions of diseased myocardium in patients with coronary artery disease.
\end{abstract}

\section{INTRODUCTION}

The means by which nitroglycerin relieves anginal pain in patients with coronary artery disease has not been clear. Although nitroglycerin induces visible arterial dilatation on the coronary angiogram (1), there have been conflicting reports as to whether coronary blood

Dr. Horwitz was a U. S. Public Health Service Special Research Fellow of the National Heart Institute, 1 FO3 HE40695-01. Dr. Gorlin is an Investigator of the Howard Hughes Medical Institute.

Received for publication 6 August 1970 and in revised form 4 March 1971. flow increases (2) or is unaltered $(3,4)$. Because changes in total coronary blood flow have not been consistently demonstrable in man, it has been suggested that the effectiveness of nitroglycerin in angina pectoris is due either to generalized peripheral arterial and venous dilatation, which lowers arterial blood pressure and reduces cardiac work and energy expenditure (2-4), or to a favorable redistribution of myocardial blood flow (5). It is characteristic of hearts involved with coronary artery disease that blood flow is nonuniform with patchy areas of poor perfusion. It is most likely that anginal pain originates from those regions where circulation is poor. Therefore, changes in flow in inadequately perfused zones are more relevant to the action of nitroglycerin than are changes in total myocardial flow or flow in major coronary arteries. Measurement of effects of nitroglycerin on local flow in diseased regions can establish whether the efficacy of the drug in angina is due to changes in myocardial perfusion or unrelated changes in cardiac mechanics or metabolism.

Sullivan, Taylor, Elliott, and Gorlin (6) used direct intramyocardial injection of an inert radioactive gas to measure regional myocardial circulation in diseased human hearts. This communication reports on the use of this technique to investigate the effect of sublingual nitroglycerin on myocardial blood flow in poorly perfused regions.

\section{METHODS}

Nine men and one woman, ranging in age from 35 to $55 \mathrm{yr}$, were studied during thoracotomy for bilateral internal mammary artery implantations. The patients had been selected for surgery because of intense and disabling anginal pain which was not well controlled by medical therapy. All subjects reported that nitroglycerin usually relieved their pain within $3 \mathrm{~min}$. Selective coronary angiography had been performed before surgery by the Sones technique utilizing a 9 in.-6 in. General Electric image intensifier and recording on Ilford Pan F $16 \mathrm{~mm}$ film at 60 frames/sec. All patients 
had films of excellent radiographic quality. Each subject had disease of all three major coronary artery systems: right, left anterior descending, and left circumflex coronary arteries and their branches. Lesions varied from minor narrowing or irregularity of the lumen to total occlusion. Prominent collateral vessels were present in most patients.

The procedure and its objectives were carefully explained to each patient before surgery, and written consent was obtained. In addition to investigation of effects of nitroglycerin, the isotope injections were used to help locate the most suitable sites for implantation of the internal mammary arteries: regions with reduced but not absent flow (6).

Nine subjects were anesthetized with halothane, nitrous oxide, and either anectine or curare; one was anesthetized with nitrous oxide, morphine, and curare. A midline sternotomy was performed, both internal mammary artery pedicles mobilized, and the pericardium opened before the study. The patients were ventilated with $100 \%$ oxygen during surgery. Mean blood gases at the time of the study were $\mathrm{pH} 7.54 \pm 0.05$ (sD), $\mathrm{PAO}_{2} 193 \pm 36 \mathrm{~mm} \mathrm{Hg}$, and $\mathrm{PAco}_{2} 29 \pm 5$ $\mathrm{mm} \mathrm{Hg}$.

The region studied was in the distribution of the left anterior descending coronary artery on the anterior wall of the left ventricle. Regions with reduced but not absent flow were sought (Fig. 1). A single injection site was used in each patient.

The sites were graded by vascularity as interpreted from preoperative coronary angiograms and appearance at surgery. Grade I sites were normal in appearance and had a normal vascular supply by angiography. Grade II sites had either a potentially decreased vascular supply by angiography (at least a $75 \%$ stenosis in the left anterior descending artery) and normal appearance, or a normal vascular supply but a pale appearance. Grade III sites had both vascular impairment by angiography and pale coloration. Grade IV sites had extensive visible scarring together with a markedly impaired vascular supply, usually total occlusion of the left anterior descending artery. There were two grade II, six

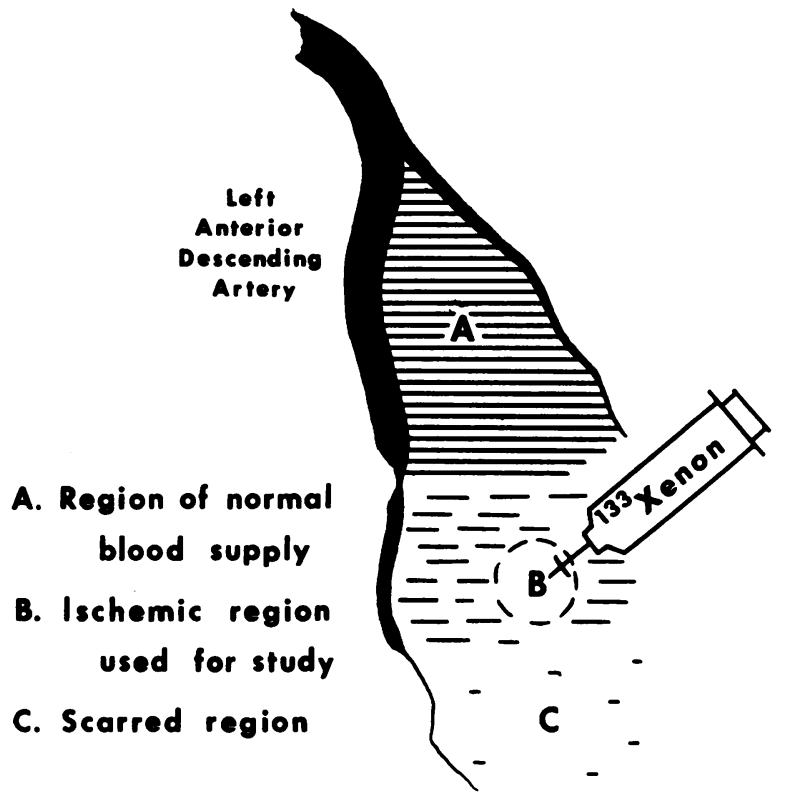

FigURE 1 Schematic to illustrate type of injection site used, regions with reduced but not absent flow.

grade III, and two grade IV sites. No grade I sites were studied. Only regions which appeared to be contracting normally were used; five patients had localized abnormalities of left ventricular contraction, but these asynergic regions were avoided.

Intramyocardial injections were made perpendicularly through a 25 gauge needle with a flange adjusted so that injections were made $3 \mathrm{~mm}$ below the epicardial surface. 0.1 $\mathrm{ml}$ (approximaately $0.15 \mathrm{mCi}$ ) of ${ }^{133} \mathrm{Xe}$ dissolved in saline

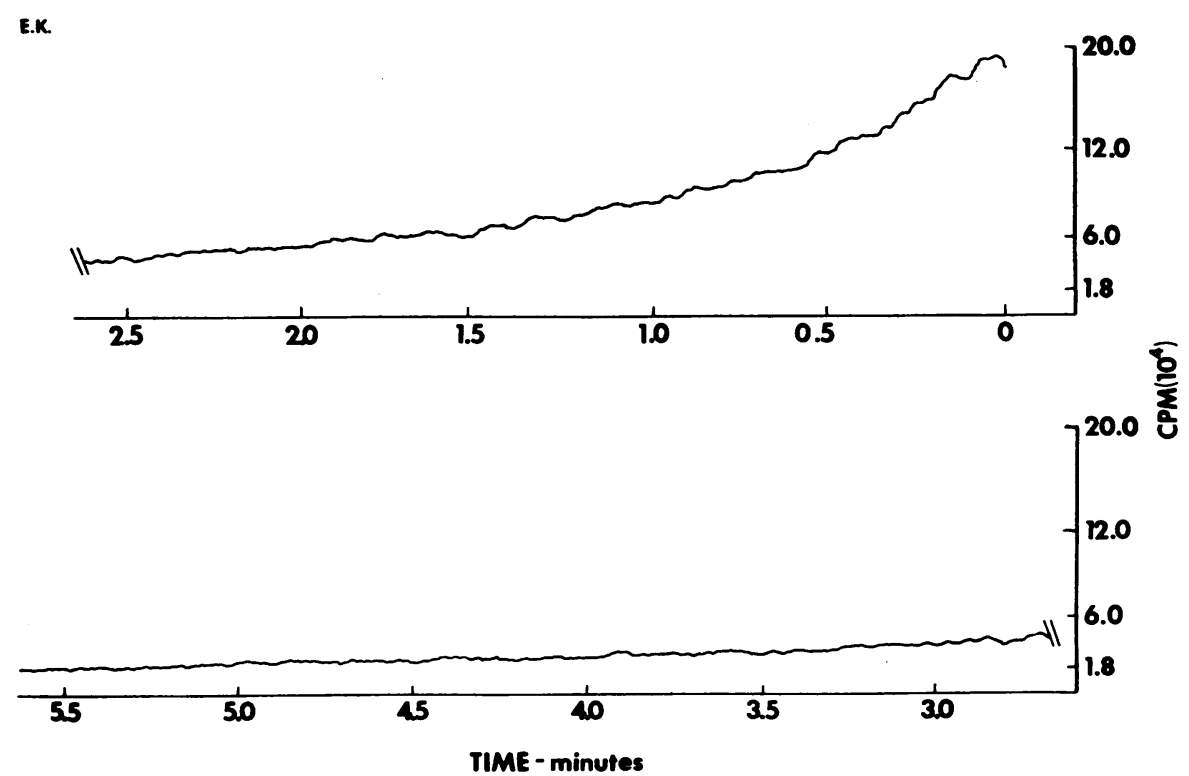

FIGURE 2 A tracing of a disappearance curve (patient E. K.). The curve is arbitrarily divided into two parts for better visualization. Time constant was $0.1 \mathrm{sec}$. $\mathrm{cpm}=$ counts per minute. 
TABLE I

Pulse Rate and Blood Pressure during Washout Curves

\begin{tabular}{|c|c|c|c|c|c|}
\hline \multirow[b]{2}{*}{ Patient } & \multirow{2}{*}{$\begin{array}{l}\text { Time } \\
\text { after } \\
\text { injection }\end{array}$} & \multicolumn{2}{|c|}{ Control } & \multicolumn{2}{|c|}{ Post-NTG } \\
\hline & & Pulse & $\begin{array}{l}\overline{\mathrm{X}} \text { Radial } \\
\text { A. Pressure }\end{array}$ & Pulse & $\begin{array}{l}\overrightarrow{\mathrm{x}} \text { Radial } \\
\text { A. Pressure }\end{array}$ \\
\hline & $\mathrm{sec}$ & $\begin{array}{l}\text { beats/ } \\
\min \end{array}$ & $m m \mathrm{Hg}$ & $\begin{array}{l}\text { beats/ } \\
\text { min }\end{array}$ & $m m \mathrm{Hg}$ \\
\hline \multirow[t]{2}{*}{ E. $\mathrm{K}$. } & 30 & 96 & 80 & 96 & 75 \\
\hline & 120 & 96 & 80 & 96 & 75 \\
\hline \multirow[t]{2}{*}{ J. D. } & 30 & 80 & 75 & 108 & 80 \\
\hline & 120 & 85 & 75 & 100 & 75 \\
\hline \multirow[t]{2}{*}{ J. B. } & 30 & 85 & 70 & 85 & 70 \\
\hline & 120 & 90 & 100 & 90 & 80 \\
\hline \multirow[t]{2}{*}{ W. R. } & 30 & 84 & 90 & 88 & 85 \\
\hline & 120 & 80 & 90 & 88 & 85 \\
\hline \multirow[t]{2}{*}{ C. M. } & 30 & 100 & 85 & 90 & 70 \\
\hline & 120 & 88 & 85 & 88 & 75 \\
\hline \multirow[t]{2}{*}{ W. M. } & 30 & 52 & 70 & 78 & 80 \\
\hline & 120 & 54 & 70 & 78 & 80 \\
\hline \multirow[t]{2}{*}{ G. K. } & 30 & 65 & 80 & 88 & 80 \\
\hline & 120 & 75 & 70 & 92 & 80 \\
\hline \multirow[t]{2}{*}{ A. A. } & 30 & 98 & 85 & 96 & 90 \\
\hline & 120 & 98 & 85 & 88 & 85 \\
\hline \multirow[t]{2}{*}{ F. L. } & 30 & 64 & 75 & 72 & 75 \\
\hline & 120 & 72 & 85 & 72 & 85 \\
\hline \multirow[t]{2}{*}{ P. I. } & 30 & 75 & 90 & 70 & 110 \\
\hline & 120 & 75 & 90 & 70 & 110 \\
\hline
\end{tabular}

$\overline{\mathrm{X}}$ Radial $\mathrm{A}$. Pressure $=$ mean pressure from radial artery cannula.

was injected. After each injection the area was wiped off with a sponge and then rinsed with saline to remove any injectate extruded to the surface. A shielded scintillation probe with a $1 \mathrm{in}$. sodium iodide crystal was positioned approximately $8 \mathrm{~cm}$ above the injection site. Counts were recorded with an analog, linear ratemeter (Picker Labmeter I) set at a time constant of either 0.1 or $0.3 \mathrm{sec}$, connected to a Picker 2990 rectilinear strip chart recorder. Counting was continued until the activity had decreased to a steady state near the zero base line-usually 3-5 min (Fig. 2). Flows were calculated from the formula $\mathrm{F}=(k \cdot \lambda \cdot \mathrm{w}) / P$ in which the clearance constant $k=0.6931 /$ (half-time in minutes) $\lambda=$ the myocardium-to-blood partition coefficient for Xe (0.7) (7), w $=100$, since the weight of myocardium is not known and by convention flow is expressed in terms of $100 \mathrm{~g}$ of tissue, and $P=1.05$, the specific gravity of myocardium $(7,8)$. As discussed in the results, the nature of the disappearance curves made a compartmental analysis appropriate (9) .

After the control curve had been obtained, a $0.4 \mathrm{mg}$ nitroglycerin (glyceryl trinitrate) tablet was rubbed against the underside of the patient's tongue with a sponge until it dissolved. Approximately $5 \mathrm{~min}$ later, the flow measurement was repeated with injection as near as possible to the same site as the control. The electrocardiogram and mean radial artery pressure were monitored continuously during all determinations.

In seven patients, an intravenous infusion of phenylephrine was running during the study period to aid the anesthetist in maintaining a stable blood pressure. Within $3 \mathrm{~min}$ after nitroglycerin was administered, mean arterial pressure fell, while pulse rate usually increased. In three of these patients the rate of infusion of phenylephrine was increased to restore pressure toward its previous level; in the other four patients receiving phenylephrine, the rate of infusion was constant during both control and the administration of nitroglycerin. In three subjects pressure had returned to near or above the level of the control study spontaneously by the time of the second injection. With or without phenylephrine infusion during the second flow state, three patients had essentially the same pressures as during the control period, three pressures above control, and four pressures stable but below control values (Table I). Pulse rate was essentially unchanged in four patients, slightly increased in four patients, and slightly decreased in two patients after nitroglycerin (Table I). Whether phenylephrine was given was decided independently by the anesthetist and was related not to the design of the study but to maintenance of stable blood pressure throaghout the operation.

\section{RESULTS}

Measurement of control curves. In all 10 patients the disappearance curves were well described by resolution into two exponential decays: an early rapid and a slow terminal clearance. In all cases a double exponential more accurately described the curves than a single exponential, while use of a third exponential term did not improve the fit. The curves were analyzed by a compartmental analysis (9). On a semilogarithmic plot, a straight line was drawn through the terminal monoexponential portion of the curve and extrapolated to zero time. The points on the extrapolated line were subtracted from the original curve to produce a new curve (Fig. 3). Two parallel flow compartments were thus defined. The mean flow in the rapid compartment was $98 \mathrm{ml} / 100 \mathrm{~g}$ per min, ranging from $10 \mathrm{ml} / 100 \mathrm{~g}$ per min in a heavily scarred region to $185 \mathrm{ml} / 100 \mathrm{~g}$ per min in a less diseased region. Mean flow in the slow compartment was $12 \mathrm{ml} / 100 \mathrm{~g}$ per min, ranging from $3 \mathrm{ml} / 100$ $\mathrm{g}$ per min to $26 \mathrm{ml} / 100 \mathrm{~g}$ per min (Tables II and III).

Average flow was calculated by dividing the contribution of each flow component according to the counts per minute at the zero time intercepts $(1,16)$. The count level at the zero time intercept of the slow flow component divided by the total number of counts at zero time is the fraction of the injected tissue mass perfused at the slow flow rate $\left(F_{s}\right)$. Therefore, $\left(1-F_{s}\right)$ is the fraction of the injected tissue mass perfused at the fast flow rate. To calculate average flow:

Average flow $=F_{s}$. Slow flow $(\mathrm{ml} / 100 \mathrm{~g}$ per $\mathrm{min}) \quad(\mathrm{ml} / 100 \mathrm{~g}$ per $\mathrm{min})$

$$
+\left(1-F_{s}\right) \underset{(\mathrm{ml} / 100 \mathrm{~g} \text { per } \min )}{\text { Fast flow. }}
$$


j.D.

CONTROL

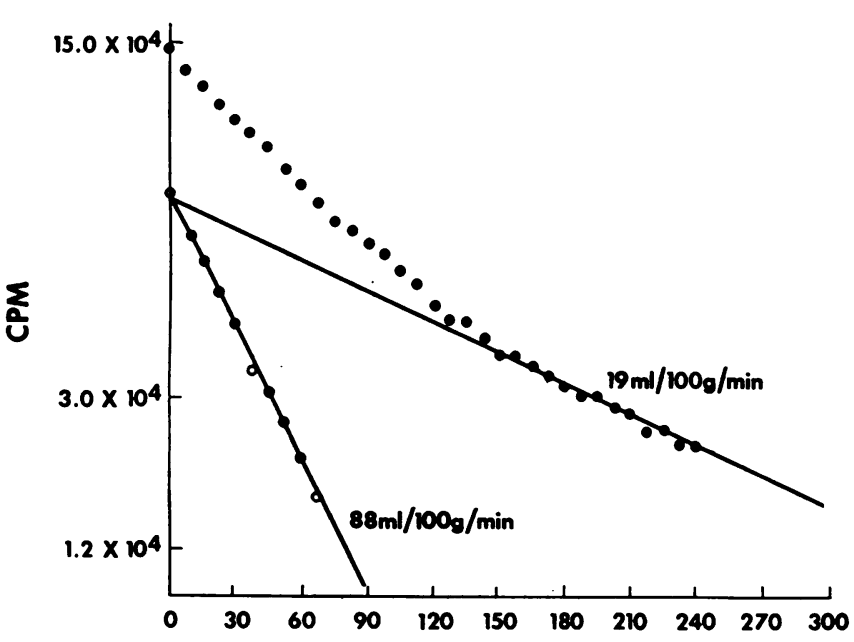

NITROGLYCERIN

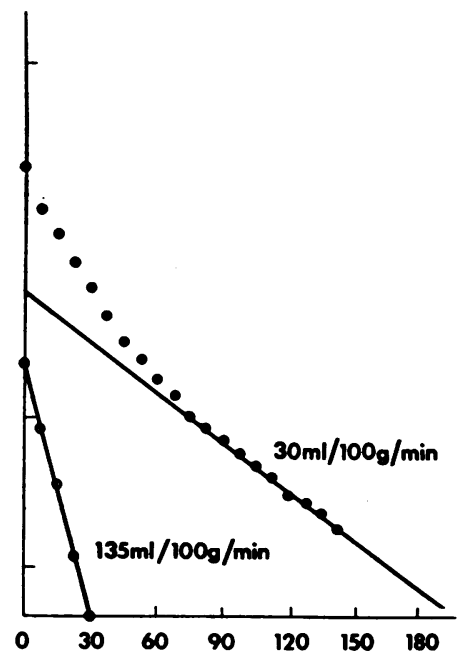

\section{SECONDS}

FIGURE 3 Semilogarithmic plots of control and nitroglycerin disappearance curves in patient J. D. A line is drawn through the terminal monoexponential portion of the curve to extrapolate this phase to zero time. The extrapolated points were subtracted from the original curve to produce a new curve, shown by the open circles, which is the fast flow component.

In the control curve in Fig. 3 , total activity at zero time was approximately $15 \times 10^{4} \mathrm{cpm}$, and activity at the zero intercept of the terminal monoexponential decay was approximaately $10.5 \times 10^{4}$. Therefore, $\mathrm{F}_{\mathrm{s}}=$ 0.7 and $\left(1-\mathrm{F}_{\mathrm{s}}\right)=0.3$. Slow flow is $19 \mathrm{ml} / 100 \mathrm{~g}$ per min, and fast flow is $88 \mathrm{ml} / 100 \mathrm{~g}$ per min so that:

Average flow $=0.7 \cdot 19+0.3 \cdot 88=40 \mathrm{ml} / 100 \mathrm{~g}$ per min.

Average flows in the control state ranged from $5 \mathrm{ml} /$ $100 \mathrm{~g}$ per min to $113 \mathrm{ml} / 100 \mathrm{~g}$ per min.

Effects of nitroglycerin. The postnitroglycerin curves also were best described by two exponential decay rates. In 9 of the 10 subjects, the fast flow increased after nitroglycerin. The mean increase was $19 \mathrm{ml} / 100 \mathrm{~g}$ per min, or $19 \%$, and the change was statistically significant with $P<0.01$ by the paired comparisons methods (Table II). The rapid flow component decreased by $5 \%$ in one patient (J. B.). Blood pressure showed a divergent response at $120 \mathrm{sec}$ between control and drug observations.

The slow flow component increased after nitroglycerin in seven patients; in two there was a decrease and in one no change. The mean increase of $3 \mathrm{ml} / 100 \mathrm{~g}$ per min, or $25 \%$, was significant $(P<0.05)$. Average flow increased in 9 of the 10 patients. The mean increase of $10 \mathrm{ml} / 100 \mathrm{~g}$ per min or $20 \%$ was also significant $(P<$ 0.01 ). The per cent of the injected tissue mass perfused at each flow rate was the same for both control and nitroglycerin curves in each of seven subjects; $F_{s}$ in- creased in one subject and decreased in two subjects after nitroglycerin. Fig. 4 shows semilogarithmic plots of four studies demonstrating several variations in the curves obtained.

TABLE II

Regional Myocardial Blood Flow before and after Nitroglycerin

\begin{tabular}{|c|c|c|c|c|c|c|}
\hline \multirow[b]{2}{*}{ Patient } & \multicolumn{2}{|c|}{ Fast flow } & \multicolumn{2}{|c|}{ Slow flow } & \multicolumn{2}{|c|}{ Average flow } \\
\hline & CON & NTG & CON & NTG & CON & NTG \\
\hline & \multicolumn{2}{|c|}{$\begin{array}{l}\mathrm{ml} / 100 \mathrm{~g} \\
\text { per min }\end{array}$} & \multicolumn{2}{|c|}{$\begin{array}{l}\mathrm{ml} / 100 \mathrm{~g} \\
\text { per min }\end{array}$} & \multicolumn{2}{|c|}{$\begin{array}{c}\mathrm{ml} / 100 \mathrm{~g} \\
\text { per min }\end{array}$} \\
\hline E. K. & 107 & 145 & 17 & 18 & 80 & 107 \\
\hline J. D. & 88 & 135 & 19 & 30 & 40 & 62 \\
\hline J. B. & 135 & 128 & 26 & 21 & 113 & 90 \\
\hline W. R. & 185 & 210 & 13 & 20 & 82 & 96 \\
\hline C. M. & 149 & 160 & 8 & 12 & 50 & 71 \\
\hline W. M. & 87 & 92 & 8 & 13 & 44 & 49 \\
\hline G. K. & 70 & 92 & 13 & 13 & 36 & 45 \\
\hline A. A. & 73 & 105 & 6 & 5 & 23 & 30 \\
\hline F. L. & 10 & 19 & 3 & 5 & 5 & 9 \\
\hline P. I. & 77 & 88 & 4 & 10 & 33 & 49 \\
\hline Mean & 98 & 117 & 12 & 15 & 51 & 61 \\
\hline SD & 49 & 51 & 7 & 8 & 32 & 31 \\
\hline$P$ & & $<0.01$ & & $<0.05$ & & $<0.01$ \\
\hline
\end{tabular}

$\mathrm{CON}=$ control $; \mathrm{NTG}=$ nitroglycerin state. $P$ is probability value obtained by paired comparison of per cent changes. 
TABLE III

Mean Control Flows and Injection Sites

\begin{tabular}{|c|c|c|c|c|}
\hline Sites & $\begin{array}{c}\text { No. of } \\
\text { patients }\end{array}$ & Fast flow & Slow flow & Average flow \\
\hline & & $\begin{array}{l}\mathrm{ml} / 100 \mathrm{~g} \\
\text { per min }\end{array}$ & $\begin{array}{l}\mathrm{ml} / 100 \mathrm{~g} \\
\text { per min }\end{array}$ & $\begin{array}{l}\mathrm{ml} / 100 \mathrm{~g} \\
\text { per min }\end{array}$ \\
\hline Grade II & 2 & 103 & 20 & 75 \\
\hline Grade III & 6 & 98 & 12 & 53 \\
\hline Grade IV & 2 & 44 & 4 & 19 \\
\hline
\end{tabular}

\section{DISCUSSION}

In 1949 Kety asserted that a diffusible indicator injected into a tissue will be cleared at a rate determined by the local blood flow (8). Subsequently, direct intramyocardial injection of inert radioactive tracers has been utilized for measurement of effective regional myocardial blood flow in dogs $(10-13)$ and man $(6,14)$. Each disappearance curve approximates one or more exponential decays, and a clearance constant can be calculated for each decay. If the myocardium-to-blood partition coefficient of the tracer is known, flow per mass of myocardium (milliliter per minute per 100 gram) can be calculated.

It is assumed that the rate of diffusion of tracer into the blood flow is not a limiting factor. The initial regional blood flow studies were done with radioactive sodium, which is insoluble in lipids and is less diffusible than lipid-soluble substances such as krypton or xenon. Both ${ }^{133} \mathrm{Xe}$ and ${ }^{85} \mathrm{Kr}$ are chemically and physiologically inert, highly diffusible through cell membranes, rapidly excreted via the lungs, safe from the standpoint of

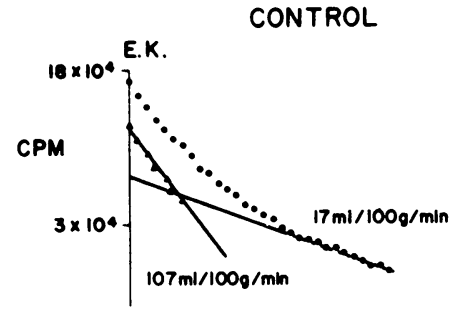

\section{NITROGLYCERIN}
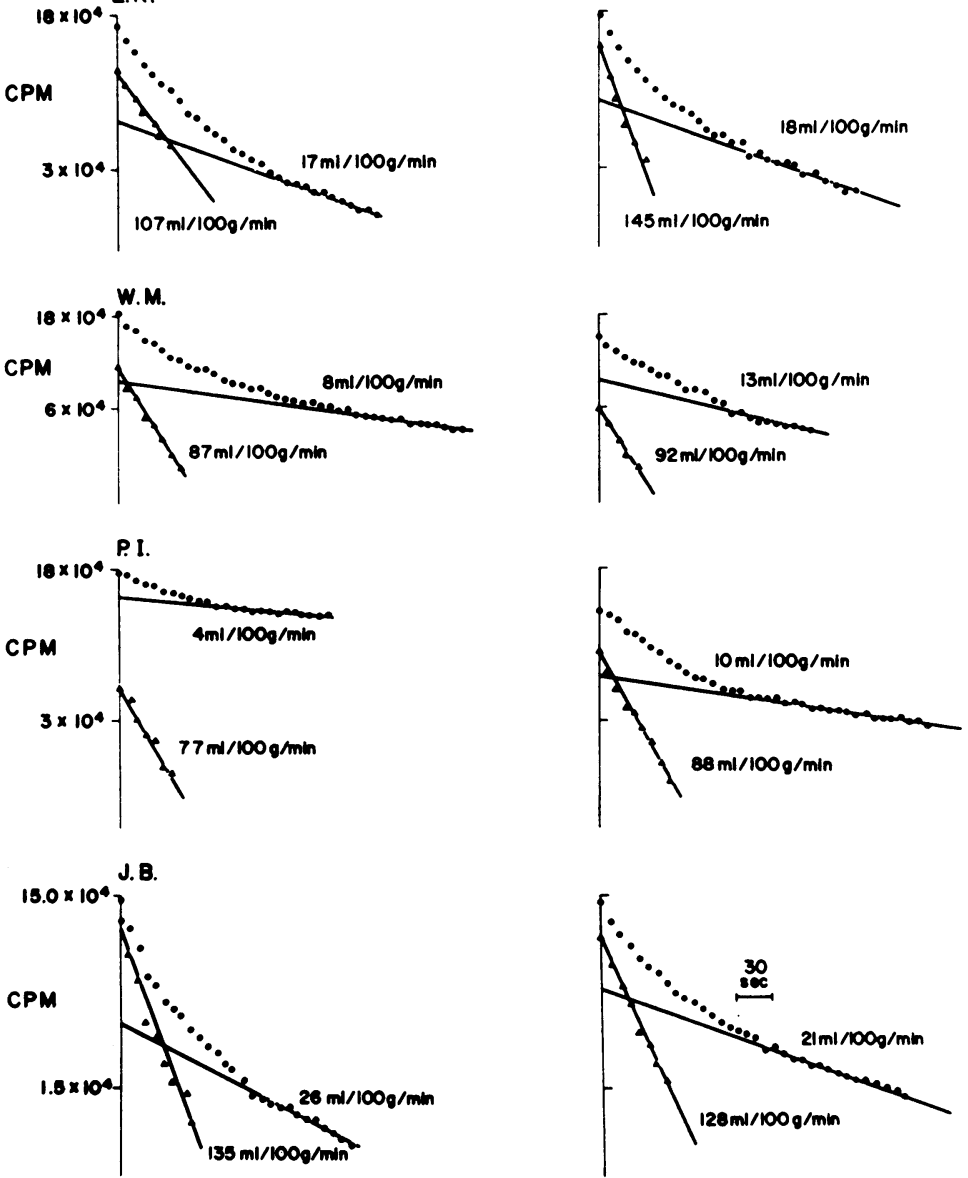

Figure 4 Composite of semilogarithmic plots of control and nitroglycerin disappearance curves in four patients. Patient E. K. had a large increase in the fast flow component and only a slight increase in the slow flow component. In W. M. the most striking increase was in the slow flow, whereas P. I. increased both components substantially. J. B. was the only patient in whom both fast and slow components decreased. 
radiation hazard, and capable of emitting adequate radiation for external counting. ${ }^{133} \mathrm{Xe}$ has several advantages over ${ }^{85} \mathrm{Kr}:{ }^{133} \mathrm{Xe}$ is more soluble in blood and myocardium, and diffusion is more rapid, its higher gamma incidence allows greater counting precision, and its shorter half-life makes the danger of radiation exposure negligible (15). Paired samples of washout curves obtained with intramyocardial ${ }^{123} \mathrm{Xe}$ or ${ }^{88} \mathrm{Kr}$ injections have been shown in previous studies to vary by $15 \%$ in normal dogs and $10 \%$ in human hearts with diseased coronary arteries $(6,13)$. Paired controls in two patients in this study varied by 5 and $10 \%$. The average increase in flow induced by nitroglycerin not only was significant but exceeded these reported ranges of paired sample variation.

All the washout curves in this study could be resolved into a rapid and a slow washout rate. It is unlikely that the slow washout was artifactual. Over $95 \%$ of the indicator is removed in a single circulation through the lungs, and less than $1 \%$ could have recirculated to the heart. The hyperventilation assured rapid excretion from the lungs, and counts directly over the lung fields were negligible. Background in the room did not change during the procedure. The relatively short probe-to-injection-site distance assured a minimum of interference from extraneous isotope in the lungs or elsewhere, and the relatively high count level and short time constant militated against inaccuracy.

Since the curves were resolvable into two exponential decays, it would appear that two parallel perfusion systems, each with its own flow rate, were present. Johanssen, Linder, and Torsten (16) have reported that, in dogs, the washout from an intracoronary injection of ${ }^{85} \mathrm{Kr}$ was monoexponential, but when the artery was occluded immediately after the injection, the curve followed a double exponential decay pattern. The rates of the rapid and slow components were similar to those noted in this study. It is possible, therefore, that the slow component, both in dogs with an occluded coronary artery and in patients with significant obstructive coronary disease, is associated with collateral flow to the region studied. However, since some patients in whom the left anterior descending artery was totally occluded, exhibited both fast and slow flow rates, it is likely that collateral flow can at least in some cases approach normal resting perfusion rate for unit volume of muscle.

The effect of nitroglycerin on collateral blood flow has been studied in dogs. Kattus and Gregg (17) found that retrograde flow in normal dogs with an acute coronary artery ligation was small and not augmented by nitroglycerin. However, Fam and McGregor (5) reported increased retrograde flow in dogs with an occluded coronary artery when nitroglycerin was administered while perfusion pressure was held constant. In the current study of patients with coronary artery disease, both the fast and slow flow component, either or both of which may be due to collateral flow increased after nitroglycerin independently of arterial pressure.

Alternative explanations for the double exponential pattern are plausible. Heterogeneity of clearance constants may reflect heterogeneity of partition coefficients rather than differences in flow. If in the region of the injection there are two populations of cells and one, perhaps because of a higher lipid content, has greater affinity for xenon than the other, it would have a slower clearance even if flow to both populations were equal. The xenon myocardium-to-blood partition coefficient for xenon in atherosclerotic human hearts is unknown, and the figure of 0.7 used in calculations for this study is extrapolated from results in normal canine myocardium. It is quite possible that heavily damaged regions in atherosclerotic hearts have a different partition coefficient than normal myocardium; differences in clearance in different regions of such hearts may be partially or wholly due to heterogeneity of partition coefficients. If such heterogeneity is present, there still would be no effect on the validity of the response to nitroglycerin, since such physical constants would not change between control and drug measurements. The fact that large changes in flow can occur in one compartment and not in another (Fig. 4) suggests that changes in flow, rather than changes in partition coefficient, account for the changes in clearance.

Because the subjects were undergoing major surgery, several variables were of necessity poorly controlled, and the extent of the study therefore was limited. The occasional infusion of phenylephrine, blood, or other fluids may have influenced hemodynamics. Anesthetic agents, hyperoxia, hypocapnia, and alkalosis may have had effects on coronary blood flow, although these factors applied to both control and drug observations. Hyperoxia decreases coronary blood flow in dogs (18), while hypocapnia (19) and phenylephrine (20) do not have consistent effects. Whether any of these variables alters flow in poorly perfused regions of human myocardium is unknown. The short period of time available for each study permitted only a single control and a single nitroglycerin measurement. Despite the uncontrolled variables and the limited number of curves, the results of nitroglycerin administration were quite consistent from patient to patient.

Regional blood flow increased in 9 of the 10 subjects after nitroglycerin. Therefore, this study demonstrates that nitroglycerin improves blood flow to regions of poorly perfused myocardium in patients with coronary artery disease. Presumably, angina originates in such regions because flow is insufficient under increased demand either to provide adequate oxygen and nutrients to the cells or to remove pain-producing metabolites. The ability of nitroglycerin to augment myocardial blood 
flow in these regions supports the view that its efficacy in relieving anginal pain is at least partially due to this effect, independent of the drug's ability to reduce myocardial effort and oxygen consumption.

Previous studies with nitroglycerin have usually failed to demonstrate increases in total coronary blood flow or flow in major arteries $(3,4)$. However, this study indicates that whether or not total coronary blood flow changes, nitroglycerin induces a significant increase in flow to diseased regions. Redistribution of coronary blood flow, whereby a greater portion of the total is delivered to diseased regions, may represent one of the important salutary effects which nitroglycerin confers upon the patient with coronary artery disease and angina pectoris.

Kirk and Honig have shown that subepicardial flow exceeds subendocardial flow in canine hearts (12). In the human hearts of this study, it is concluded that subepicardial flow in regions where the blood supply is compromised by coronary artery disease is increased by nitroglycerin. No information is provided about total myocardial blood flow, nor were measurements performed in normal regions or in deeper layers of the myocardium where greater intramural pressure differences may alter flow responses. To clarify the mechanism of action of nitroglycerin in angina, measurements of flow in poorly perfused regions are far more valuable than estimation of total coronary blood flow, since flow changes in normally perfused regions probably do not contribute to the relief of myocardial ischemia and pain.

\section{ACKNOWLEDGMENTS}

The authors wish to express their appreciation to Dr. Jay M. Sullivan for his advice and assistance.

This work was supported by U. S. Public Health Service grant IPO 1-HE 11306.

\section{REFERENCES}

1. Likoff, W., H. Kasparian, J. S. Lehman, and B. L. Segal. 1964. Evaluation of "coronary vasodilators" by coronary arteriography. Amer. J. Cardiol. 13: 7.

2. Cowan, C., P. V. M. Duran, G. Corsini, N. Goldschlager, and R. J. Bing. 1969. The effects of nitroglycerin on myocardial blood flow in man, measured by coincidence counting and bolus injections of 84 rubidium. Amer. J. Cardiol. 24: 154.

3. Gorlin, R., N. Brachfeld, C. MacLeod, and P. Bopp. 1959. Effect of nitroglycerin on the coronary circulation in patients with coronary artery disease or increased left ventricular work. Circulation. 19: 705.
4. Bernstein, L., G. C. Friesinger, P. R. Lichtlen, and R. S. Ross. 1966. The effect of nitroglycerin on the systemic and coronary circulation in man and dogs. Myocardial blood flow measured in with xenon ${ }^{138}$. Circulation. 33: 107 .

5. Fam, W. M., and M. McGregor. 1964. Effect of coronary vasodilator drugs on retrograde flow in areas of chronic myocardial ischemia. Circ. Res. 15: 355.

6. Sullivan, J. M., W. J. Taylor, W. C. Elliott, and R. Gorlin. 1967. Regional myocardial blood flow. J. Clin. Invest. 46: 1402 .

7. Ross, R. S., K. Ueda, P. R. Lichtlen, and J. R. Rees. 1964. Measurement of myocardial blood flow in animals and man by selective injection of radioactive inert gas into the coronary arteries. Circ. Res. 15: 28.

8. Kety, S. S. 1949. Measurement of regional circulation by the local clearance of radioactive sodium. Amer. Heart J. 38: 321 .

9. Hoedt-Rasmussen, K., E. Sveinsdottir, and N. A. Lassen. 1966. Regional cerebral blood flow in man determined by intra-arterial injection of radioactive inert gas. Circ. Res. 18: 237.

10. Cullen, M. L., and H. L. Reese. 1952. Myocardial circulatory changes measured by clearance of $\mathrm{Na}^{24}$-effect of common duct distension on myocardial circulation. $J$. Appl. Phy'siol. 5: 281.

11. Salisbury, P. F., C. E. Cross, R. W. Oblath, and P. A. Rieben. 1962. Local circulation of heart muscle studied with $\mathrm{Na}^{24}$ clearance method. J. Appl. Physiol. 17: 475.

12. Kirk, E. S., and C. R. Honig. 1964. Nonuniform distribution of blood flow and gradients of oxygen tension within the heart. Amer. J. Physiol. 207:661.

13. Brandi, G., W. M. Fam, and M. McGregor. 1968. Measurement of coronary flow in local areas of myocardium using xenon ${ }^{133}$.J. Appl. Physiol. 24: 446.

14. Hollander, W., I. M. Madoff, and A. V. Chobanian. 1963. Local myocardial blood flow as indicated by the disappearance of $\mathrm{NaI}^{131}$ from the heart muscle: studies at rest, during exercise and following nitrite administration. J. Pharmacol. Exp. Ther. 139: 53.

15. Wagner, H. N., Jr. 1964. Regional blood-flow measurements with krypton ${ }^{85}$ and $x^{2}$ non $^{133}$. AEC Symp. Ser. 3: 189.

16. Johansson, B., E. Linder, and T. Seeman. 1964. Collateral blood flow in the myocardium of dogs measured with krypton $^{85}$. Acta Physiol. Scand. 62: 263.

17. Kattus, A. A., and D. E. Gregg. 1959. Some determinants of coronary collateral blood flow in the openchest dog. Circ. Res. 7: 628.

18. Sobol, B. J., S. A. Wanlass, E. B. Joseph, and I. Azarshahy. 1963. Alteration of coronary blood flow in the dog by inhalation of 100 per cent oxygen. Circ. Res. $11: 797$.

19. Feinberg, H., A. Gerola, and L. N. Katz. 1960. Effect of change in blood $\mathrm{CO}_{2}$ level on coronary flow and myocardial $\mathrm{O}_{2}$ consumption. Amer. J. Physiol. 199: 349.

20. Haddy, F. J. 1969. Physiology and pharmacology of the coronary circulation and myocardium particularly in relation to coronary artery disease. Amer. J. Med. 47: 274. 